\title{
Azadirachta indica influenced biosynthesis of super-paramagnetic iron-oxide nanoparticles and their applications in tannery water treatment and X-ray imaging
}

\author{
Antony V. Samrot ${ }^{1} \cdot$ P. Senthilkumar ${ }^{2} \cdot$ S. Rashmitha ${ }^{2} \cdot$ Priscilla Veera $^{2} \cdot$ Chamarthy Sai Sahithya $^{1}$
}

Received: 14 July 2018 / Accepted: 23 August 2018 / Published online: 31 August 2018

(c) The Author(s) 2018

\begin{abstract}
Super-paramagnetic iron-oxide nanoparticles (SPIONs) have been exploited from a very long time and are researched profoundly due to their unique properties. In this study, SPIONs were synthesized using environmentally accepted green synthesis process where Azadirachta indica leaf extract was used as one of the reducing agents along with basic metal precursors used in chemical processes. The synthesized SPIONs were characterised using microscopic analysis (SEM, TEM, and AFM), spectroscopic analysis (FT-IR, UV-Vis, XRD, Raman, and zeta potential), and magnetometry (SQUID). The SPIONs were then tested for its application in the removal of heavy metals from tannery waste water and also X-ray imaging.
\end{abstract}

Keywords SPIONs $\cdot \mathrm{X}$ ray imaging $\cdot$ Heavy metal removal

\section{Introduction}

Nanoparticles (NPs) of size ranged between 1 and $50 \mathrm{~nm}$ have tremendous impact on various disciplines of science $[1,2]$. These particles possess unique characteristics when compared to its precursor such as optical, magnetic, electrical, electrocatalytic, hardness, strength, etc., due to its relatively smaller surface-to-volume ratio [3], and being applied in face creams, cosmetics, sports equipments, textiles, cell phones, and many other industrially important products [4]. Nanotechnology is exploited in the field of biomedical application for imaging, targeted drug delivery, biosensors, treatment, etc. [5, 6]. Apart from these, it has also found applications in environmental for cleaning up environmental pollutants [7], dye removal [8-10], waste water treatment [11], heavy metal removal [12], etc. Among the nanoparticles, specifically metal-derived nanoparticles like iron-oxide nanoparticles have pinned a lot of interest

Antony V. Samrot

antonysamrot@gmail.com

1 Department of Biotechnology, School of Bio and Chemical Engineering, Sathyabama Institute of Science and Technology, Jeppiaar Nagar, Rajiv Gandhi Salai, Sholinganallur, Chennai, Tamil Nadu 600119, India

2 Department of Chemical Engineering, School of Bio and Chemical Engineering, Sathyabama Institute of Science and Technology, Jeppiaar Nagar, Rajiv Gandhi Salai, Sholinganallur, Chennai, Tamil Nadu 600119, India among the research community. Super-paramagnetic iron-oxide nanoparticles (SPIONs) can be of different chemical makeup, such as magnetite $\left(\mathrm{Fe}_{3} \mathrm{O}_{4}\right)$ or $\alpha-\mathrm{Fe}_{2} \mathrm{O}_{3}$ (hematite) and $\gamma-\mathrm{Fe}_{2} \mathrm{O}_{3}$ (maghemite), and they have high magnetization effect under the magnetic field. However, this super-paramagnetic effect of SPIONs is size-dependent [13].

SPIONs are synthesized using chemical co precipitation method [14] which is known as one of the simplest methods than the other procedures like thermal decomposition, microemulsion, hydrothermal synthesis, sonochemical synthesis [15], pyrolysis, template-assisted synthesis, and sol-gel method [16], and is one of the easiest procedures. Usually, in chemical synthesis, the iron precursors are mixed together and reduced using a reducing agent like $\mathrm{NaOH}$, TMAOH (tetramethylammonium hydroxide), $\mathrm{NH}_{3}$, etc. [17, 18]. Use of such chemicals in the synthesis of nanoparticles may be one of the many reasons for high toxicity of ironoxide nanoparticles towards the environment [19]. Hence, plant extracts are used as reducing agents in the synthesis process, called green synthesis [20], since they are easily available, nontoxic, and have a broad variety of metabolites that help in reduction of ions [21]. In this study, Azadirachta indica was used as one of reducing agents along with other chemicals in producing SPIONs. Using the plant extract as one of the reducing agents is expected to reduce the toxicity of iron oxides as well as increases its application. Iron-oxide nanoparticles are efficient absorber of heavy metals such as 
$\mathrm{Cd}, \mathrm{Pb}, \mathrm{Cu}, \mathrm{Zn}, \mathrm{Ni}$, and $\mathrm{Cr}[11,22]$. Tannery waste water contains heavy metals like lead $(\mathrm{Pb})$, cadmium $(\mathrm{Cd})$, copper $(\mathrm{Cu})$, chromium $(\mathrm{Cr})$, etc. [23]. Even there are reports there for the presence of chromium in drinking water [24]. Thus, the produced nanoparticles were used for heavy metal removal and also as a contrasting agent in X-ray imaging of chicken egg.

\section{Materials and methods}

\section{Chemicals used}

Iron(III) chloride hexahydrate $\left(\mathrm{FeCl}_{3} \cdot 6 \mathrm{H}_{2} \mathrm{O}\right)$ and iron(II) chloride heptahydrate $\left(\mathrm{FeCl}_{2} \cdot 7 \mathrm{H}_{2} \mathrm{O}\right)$ purchased from LOBACHEMIE and sodium hydroxide purchased from SRL, India were used in this study. Fifty Gauss strength magnets were utilised for removal of SPIONs.

\section{Synthesis of iron-oxide nanoparticles}

\section{Preparation of Azadirachta indica leaf extract}

Azadirachta indica leaves were collected from Sathyabama Institute of Science and Technology, Chennai, Tamil Nadu, India, and washed thoroughly using distilled water. They were shade dried and ground to powder. $10 \mathrm{~g}$ of powdered Azadirachta indica leaves were subjected to aqueous extraction by adding $100 \mathrm{ml}$ of deionized sterile water. The mixture was kept in shaker for $24 \mathrm{~h}$ and then filtered using Whatman No. 1 filter paper. The resultant filtrate was used in the synthesis of iron-oxide nanoparticles.

\section{Synthesis of SPIONs by coprecipitation method}

$0.12 \mathrm{~g}$ of $\mathrm{FeCl}_{3} \cdot 6 \mathrm{H}_{2} \mathrm{O}$ and $0.6 \mathrm{~g}$ of $\mathrm{FeCl}_{2} \cdot 7 \mathrm{H}_{2} \mathrm{O}$ were taken separately in $50 \mathrm{ml}$ of nitrogenized MilliQ water. These two solutions were mixed together in the ratio of 2:1 and heated at $60{ }^{\circ} \mathrm{C}$ for $5 \mathrm{~min}$ under continuous stirring. Solution was allowed to cool and $10 \mathrm{ml}$ of prepared Azadirachta indica leaf extract was added slowly with continuous stirring; following that, $25 \mathrm{ml}$ of $0.1 \mathrm{~N} \mathrm{NaOH}$ was added dropwise as stirring was continued [25]. The solution was left undisturbed until the black-coloured precipitate was obtained, which was separated using a magnetic bar, washed thrice with MilliQ water, and lyophilized to obtain powdered particles. These particles were used for further studies.

\section{Characterization of SPIONs}

The produced SPIONs were subjected for UV-visible spectroscopy analysis (UV 3600, Shimadzu), Fourier transform infrared spectroscopy (FT-IR) analysis (IR Affinity-1s,
Shimadzu), scanning electron microscopy (FeSEM) (Zeiss Ultra55), transmission electron microscopy (TEM) (TEECNAI G2 Spirit Biotwin), atomic force microscopy (AFM) (Bruker), Raman spectroscopic analysis (LabRam HR 800), X-ray diffraction spectroscopy (XRD) (Smart lab, Rigaku), X-ray photon spectroscopy (XPS) (Ultra DLD-Kratos), zeta potential analysis (Brookhaven ZetaPALS), and superconducting quantum interference device (SQUID) analysis.

\section{Heavy metal removal analysis}

$50 \mathrm{ml}$ of raw heavy metal water from tannery waste was collected. $25 \mathrm{ml}$ was digested with $10 \mathrm{ml}$ nitric acid, and after digestion, the sample was made up to $50 \mathrm{ml}$ with MilliQ water and water sample was given for ICP-OES analysis (Perkin Elmer 2000DV) to detect the initial concentrations of lead, copper, and cadmium heavy metals present in the polluted water.

The other $25 \mathrm{ml}$ collected polluted water added with $0.01 \mathrm{~g}$ of SPIONs and mixed continuously for $10 \mathrm{~min}$ and allowed to react with water for $1 \mathrm{~h}$. Later, these SPIONs were removed using a magnetic bar and the water was processed again as described earlier and given for ICP-OES analysis (Perkin Elmer 2000DV) to detect heavy metals.

\section{X-ray imaging using chicken eggs}

Chicken eggs from local shop were obtained and cleaned. About $1.5 \mathrm{ml}$ of egg's white matter was carefully sucked out. $1 \mathrm{mg} / \mathrm{ml}$ of synthesized SPIONs in distilled water was injected inside the eggs and carefully shaken to disperse the SPIONs. The eggs were visualized under X-ray machine (Wipro G machine) with the capacity of $300 \mathrm{~mA}$ and the film was taken using the computerized radiography (CR) of Fujifilm FCR Prima T. The magnetic property of SPIONs was also tested by placing the magnet near the egg.

\section{Results and discussion}

\section{Synthesis of SPIONs}

Black-coloured precipitate was obtained within $15 \mathrm{~min}$. SPIONs were separated using magnet, and it was washed and used for further study.

\section{UV-visible spectroscopy analysis}

The maximum absorbance was found to be around $250 \mathrm{~nm}$ from the graph (Fig. 1), which was the characteristic peak of SPIONs as per earlier reports $[19,26]$. There was absorbance maximum near $390 \mathrm{~nm}$ which might be conferred by plant extract. 


\section{Fourier transform infrared spectroscopy (FT-IR)}

Prominent bands in the IR range less than $569 \mathrm{~cm}^{-1}$ were considered as the finger print region for ironoxide nanoparticles depicting the $\mathrm{Fe}-\mathrm{O}$ bonds in SPIONs [27]. Bands for $\mathrm{O}-\mathrm{H}$ stretching were for adsorbed water [28, 29] (Fig. 2). Other peaks might be assumed for the polyphenols in the Azadirachta indica leaf extract which may function as reducing agent as well as capping agent.

\section{Scanning electron microscopy (FeSEM)}

SPIONs produced were in the range of $25 \mathrm{~nm}$ (Fig. 3). Awwad and Salem [25] successfully produced 5-8 nmsized magnetite using Carob leaves extract.

\section{Transmission electron microscopy (TEM)}

Iron-oxide nanoparticles were found to be on par with the SEM results (Fig. 4).

\section{Atomic force microscopy (AFM)}

The SPIONs' size range was recorded to be around $25 \mathrm{~nm}$, which was supporting the TEM and SEM image (Fig. 5).

\section{Raman spectroscopy analysis}

The following peaks at $240 \mathrm{rcm}^{-1}, 260 \mathrm{rcm}^{-1}$, and $500 \mathrm{rcm}^{-1}$ were assigned for $E_{\mathrm{g}}$ mode where the peak at $600 \mathrm{rcm}^{-1}$ was for $\mathrm{A}_{1 \mathrm{~g}}$ mode which stood for $\mathrm{Fe}_{3} \mathrm{O}_{4}$ within verse-spinel crystal structure (Fig. 6) as reported earlier [28, 30, 31].

\section{X-ray diffraction analysis (XRD)}

The sites and intensity of the diffraction peaks at 220,311, 400, 511, and 440 were for cubic spinel structure of $\mathrm{Fe}_{3} \mathrm{O}_{4}$ (JCPDS 85-1436) [32] (Fig. 7).

\section{X-ray photon spectroscopy (XPS)}

From the obtained XPS images, binding energy of $\mathrm{Fe}_{2} p_{3 / 2}$ was occurring at $711.8 \mathrm{eV}$, where the binding energy for $\mathrm{FeO}$ and $\mathrm{Fe}$ was seen at 709.6 and $706.7 \mathrm{eV}$, respectively. The peak at 531 was suggestive of metal oxide [28]. Binding energy for $\mathrm{C}-\mathrm{C}$ was observed at 285.8 , where it was $289.5 \mathrm{eV}$ for $\mathrm{O}-\mathrm{C}=\mathrm{O}$, thus, suggesting the molecular carbon's presence (Fig. 8).

\section{Zeta potential analysis}

Zeta potential of the plant-derived SPIONs was found to be $-38.62 \mathrm{mV}$ (Fig. 9). Particles with value between -30 and $+30 \mathrm{mV}$ are stable [17]. The value obtained for SPIONs in this study did not fall in between the desired range, it could
Fig. 1 UV-visible spectroscopy analysis of SPIONs

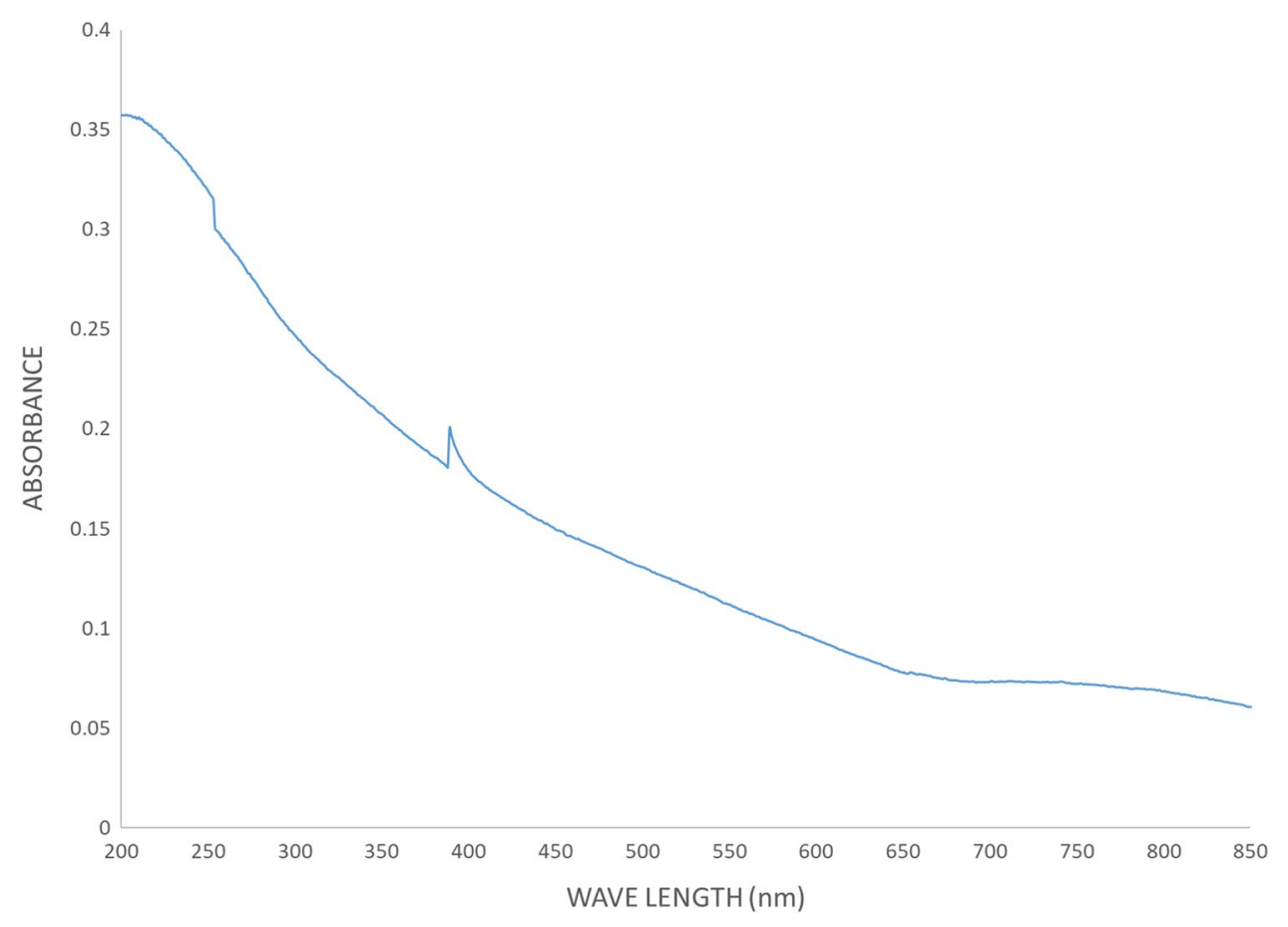


Fig. 2 Fourier transform infrared spectroscopy analysis of SPIONs. Dotted arrow represents $\mathrm{OH}$ stretching; bold arrow represents $\mathrm{Fe}-\mathrm{O}$ bond
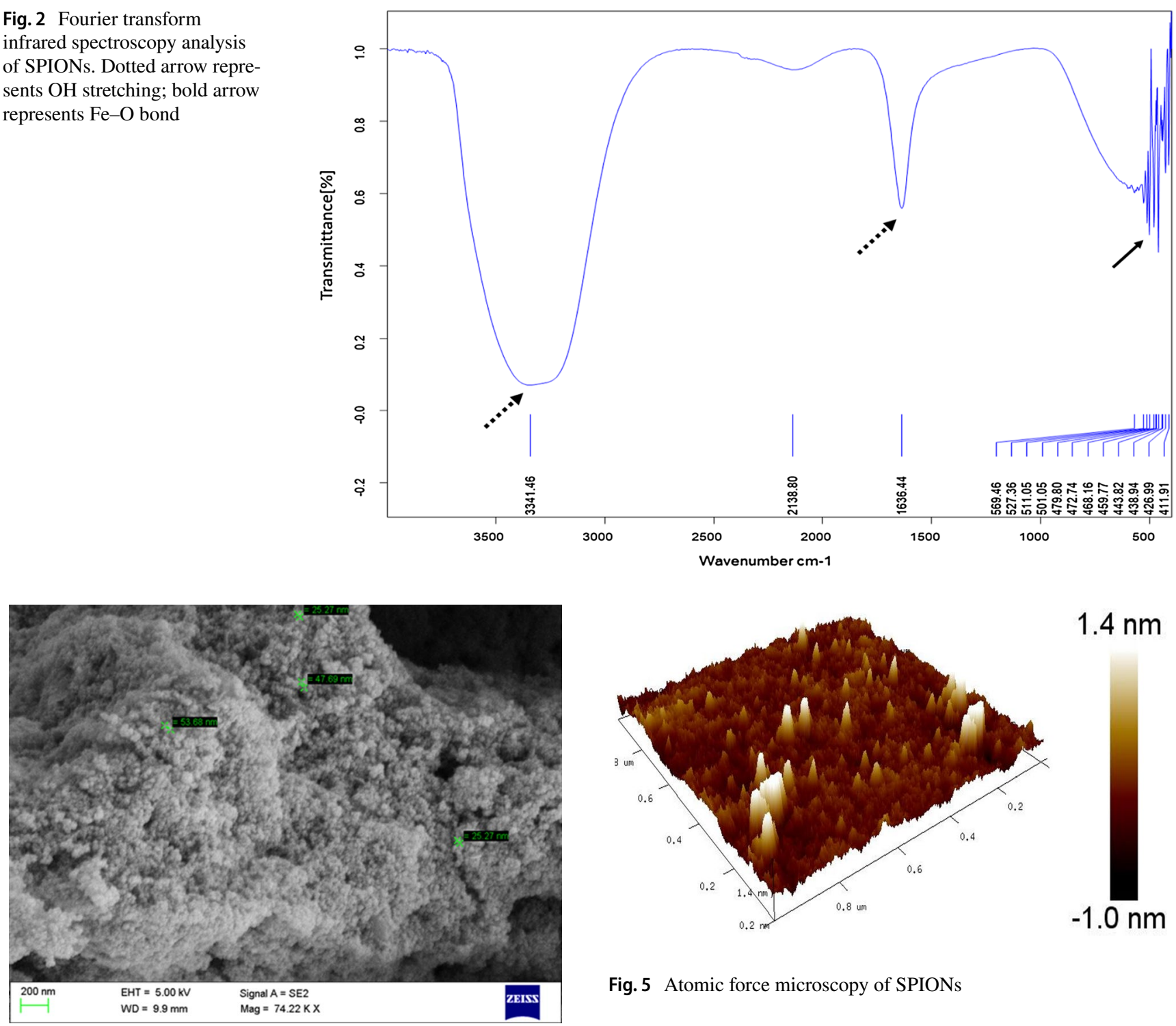

$1.4 \mathrm{~nm}$

Fig. 3 Scanning electron micrograph of SPIONs

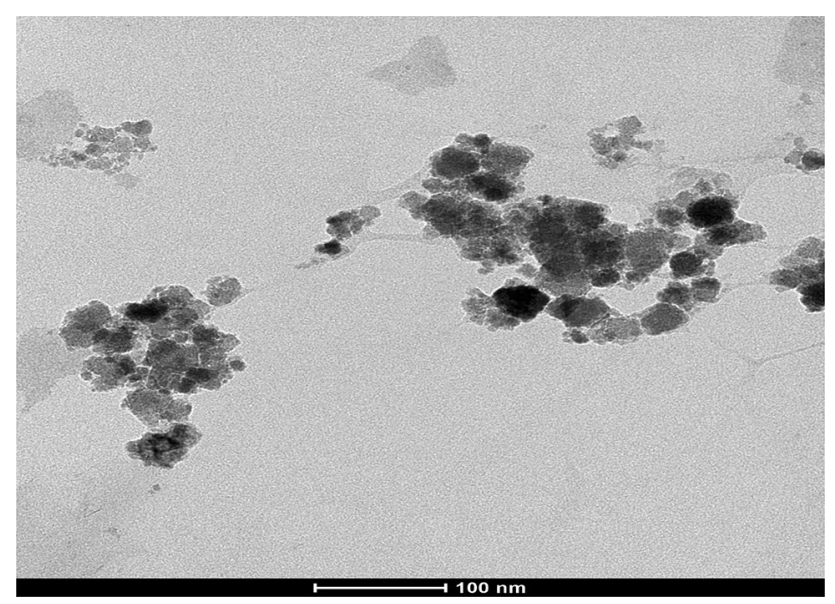

Fig. 5 Atomic force microscopy of SPIONs

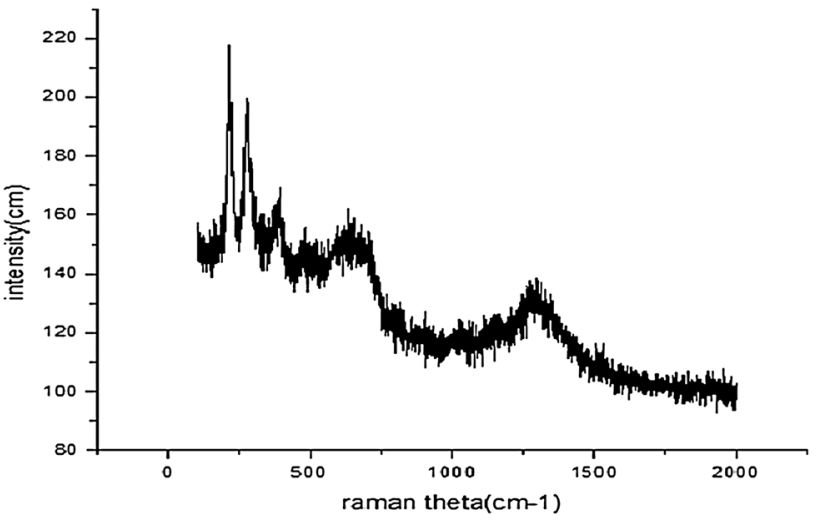

Fig. 6 Raman spectroscopy of SPIONs

Fig. 4 Transmission electron micrograph of SPIONs 
be interpreted that the SPIONs were mildly unstable and there might be chances of slight agglomeration [33, 34].

\section{Superconducting quantum interference device (SQUID)}

The magnetic moment was steadily increasing up to $200 \mathrm{~K}$ temperature and decreased at $300 \mathrm{~K}$; again, it was increasing at 300-310 K, and, finally, fell after $310 \mathrm{~K}$ (Fig. 10a). The reduction in coercivity was observed as the mean particle size was decreased [35]. At ZFC mode, the magnetic moment was very low, indicating that the magnetic moments were frozen at this temperature (5 K) (Fig. 10).

\section{Inductive coupled plasma-optical emission spectroscopy (ICP-OES)}

The three major metals lead $(\mathrm{Pb})$, copper $(\mathrm{Cu})$, and cadmium (Cd) were found in the waste water, and their concentration was observed to be reduced from 0.0020 to $<0.0000 \mathrm{ppm}$ for lead, 0.0134 to $<0.0000 \mathrm{ppm}$ for cadmium, and 0.1468 to $0.0022 \mathrm{ppm}$ for copper after treating the water with SPIONs, as shown in Table 1. The metabolites of plants would have
Table 1 ICP-OES analysis of tannery wastewater and treated with SPIONs

\begin{tabular}{lllrl}
\hline S. no. & Line & \multicolumn{2}{l}{ Concentration $(\mathrm{ppm})$} & \multirow{2}{*}{ element } \\
\cline { 3 - 3 } & & Untreated & Treated & \\
\hline 1 & $\mathrm{~Pb} 220.353$ & 0.0020 & $<0.0000$ & Lead \\
2 & $\mathrm{Cu} \mathrm{324.754}$ & 0.1468 & 0.0022 & Copper \\
3 & $\mathrm{Cd} 214.441$ & 0.0134 & $<0.0000$ & Cadmium \\
\hline
\end{tabular}

acted as the functionalizing agent and might have also influenced the absorption. Lanas [36] found SPIONs functionalized with 3-mercapto propionic acid to absorb heavy metals efficiently. Hence, iron-oxide nanoparticles can be used in wastewater treatment for the removal of the heavy metals.

\section{X-ray imaging using chick eggs}

From Fig. 11, it can be concluded that the SPIONs acted as contrasting agents and have enhanced the X-ray imaging effect, thereby visualizing yolk of the chick egg clearly. Hence, SPIONs can be used as contrasting agent since iron

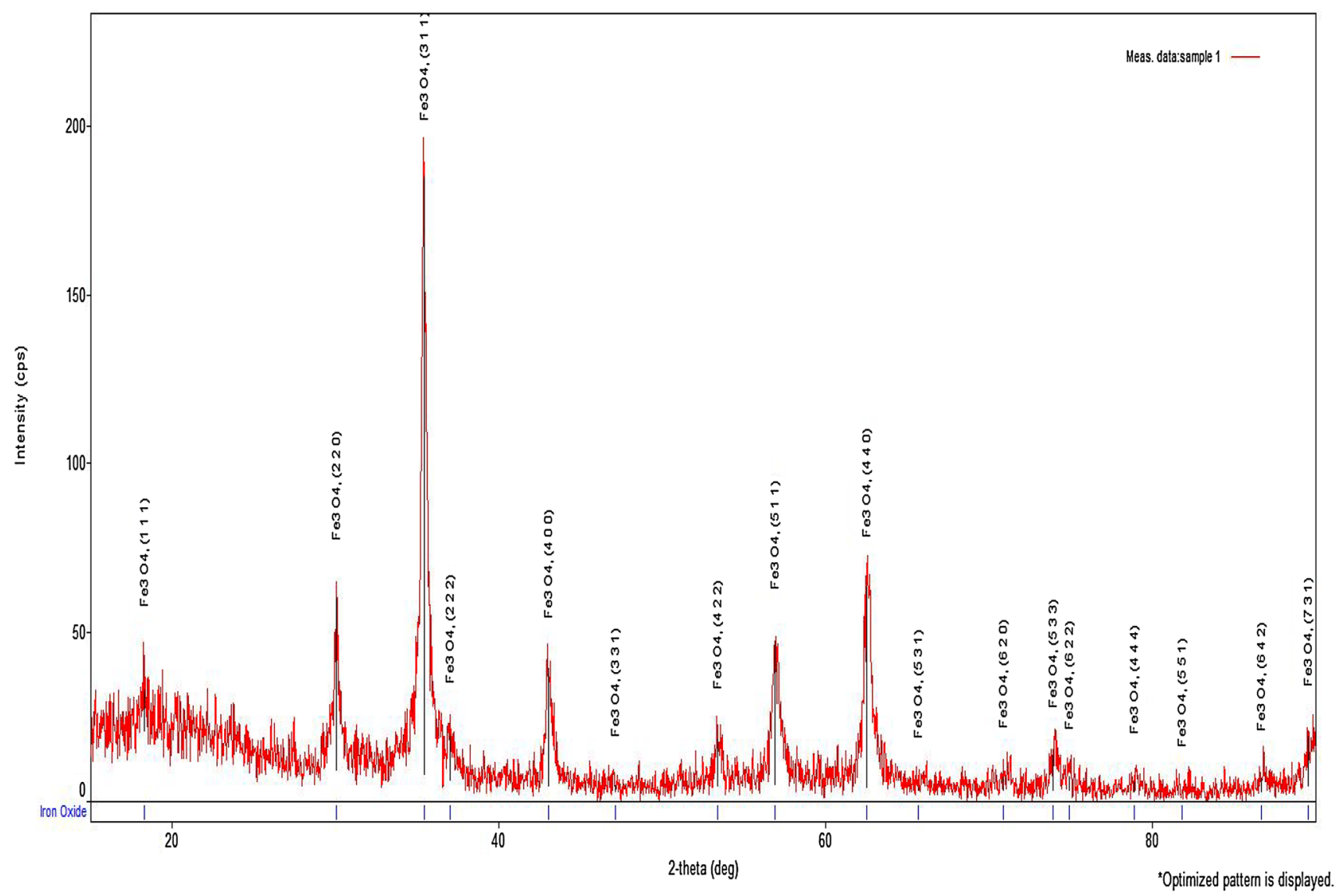

Fig. 7 X-ray diffraction analysis of SPIONs 

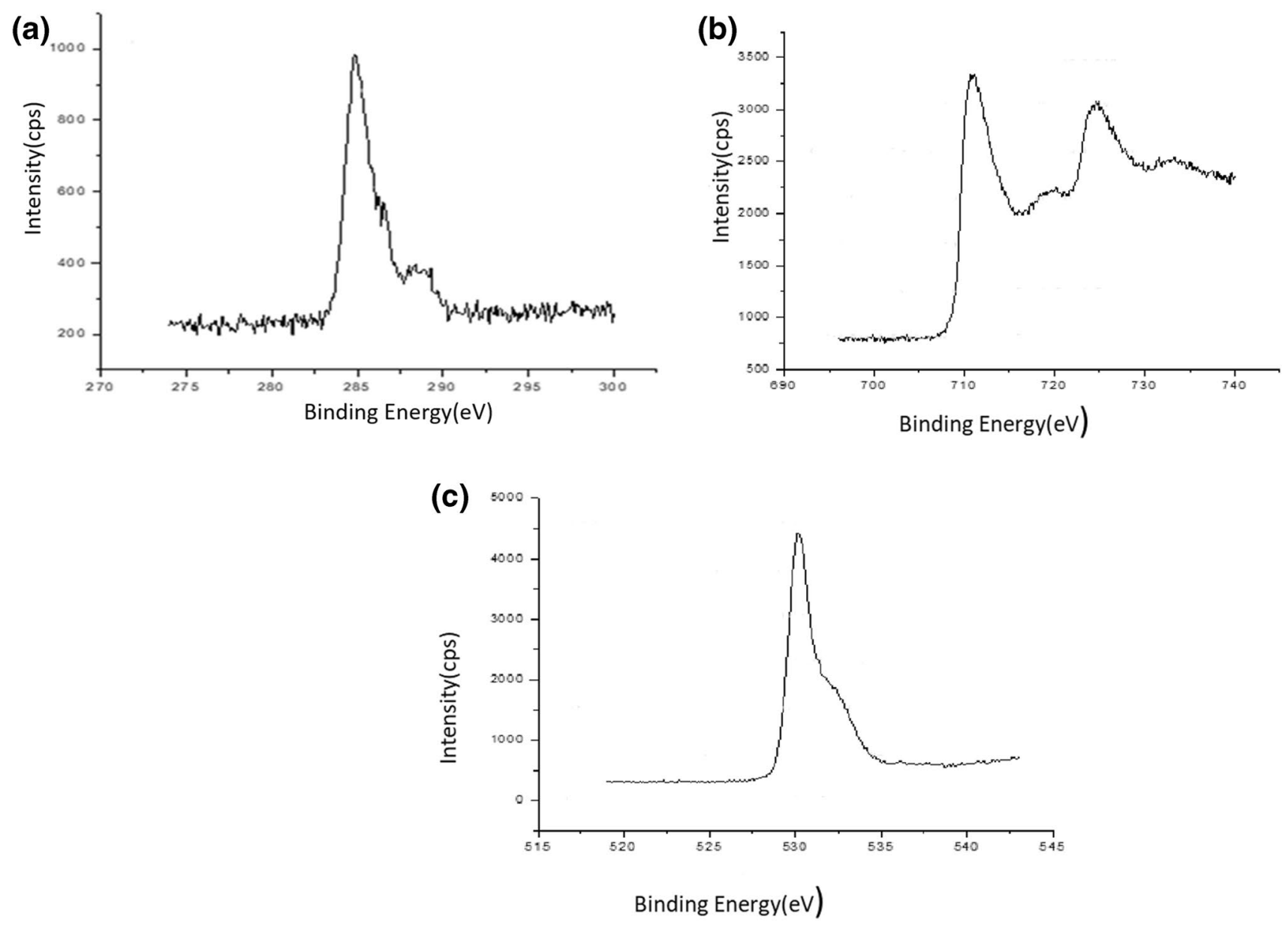

Fig. 8 X-ray photon spectroscopy of SPIONs: $\mathbf{a}$ for adventitious carbon, $\mathbf{b} \mathrm{Fe}_{2} p_{3 / 2}$, and $\mathbf{c}$ for metal oxide

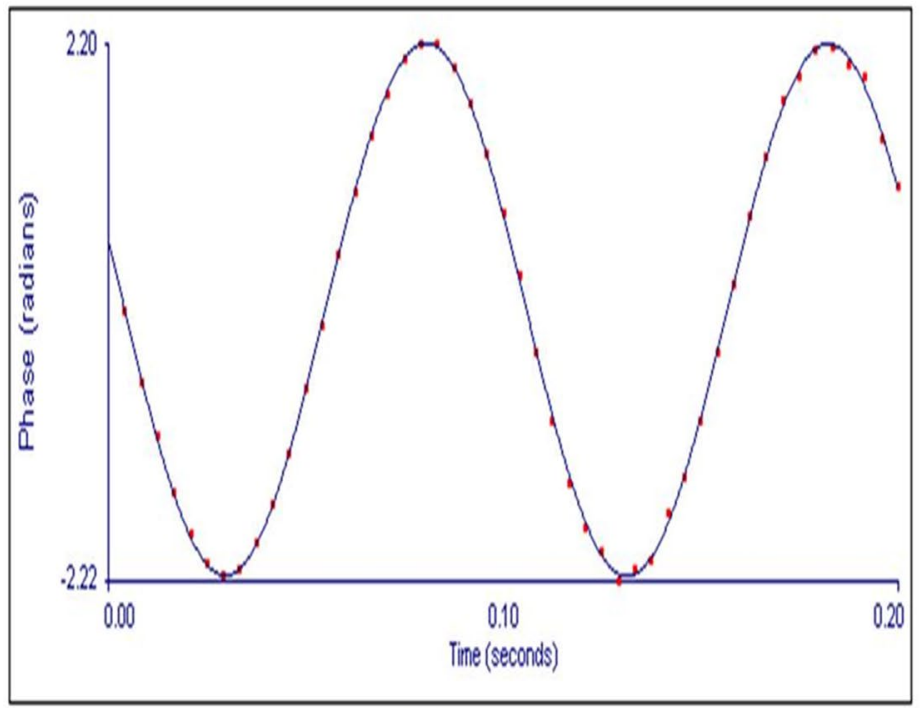

\begin{tabular}{|cccc|}
\hline Run & Mobility & Zeta Potential (mV) & Rel. Residual \\
\hline 1 & .3 .03 & .38 .74 & 0.0066 \\
2 & .3 .01 & .38 .51 & 0.0068 \\
& & & \\
& & & \\
& & & \\
& & & \\
& & & \\
& & & \\
\hline Mean & .3 .02 & .38 .62 & 0.0067 \\
Sid. Error & 0.01 & 0.12 & 0.0001 \\
Combined & .3 .02 & .38 .62 & 0.0050 \\
\hline
\end{tabular}

Fig. 9 Zeta potential of SPIONs 

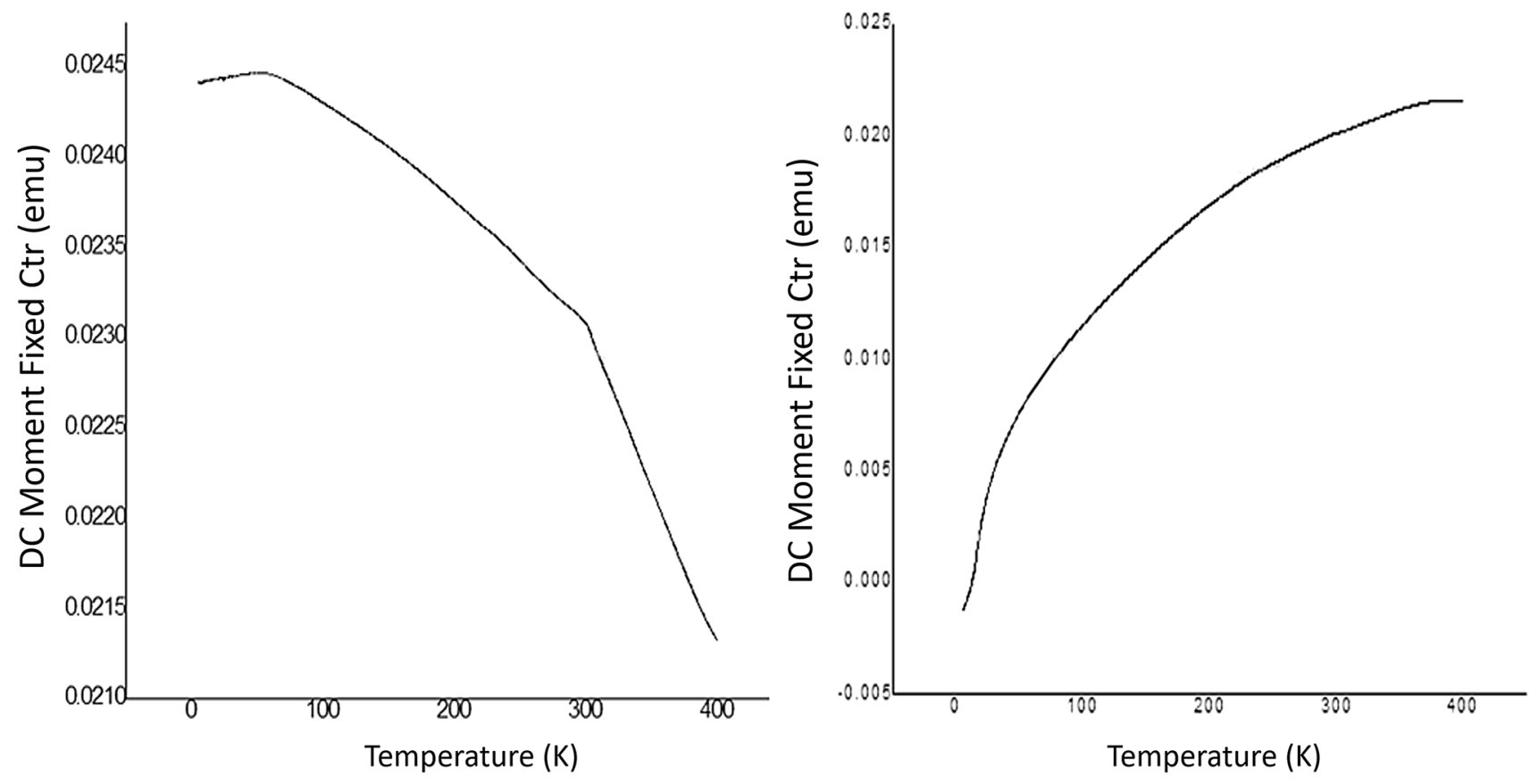

Fig. 10 SQUID analysis of SPIONs. a Field-cooled (FC) magnetization measurement, b zero-field-cooled (ZFC) magnetization measurement
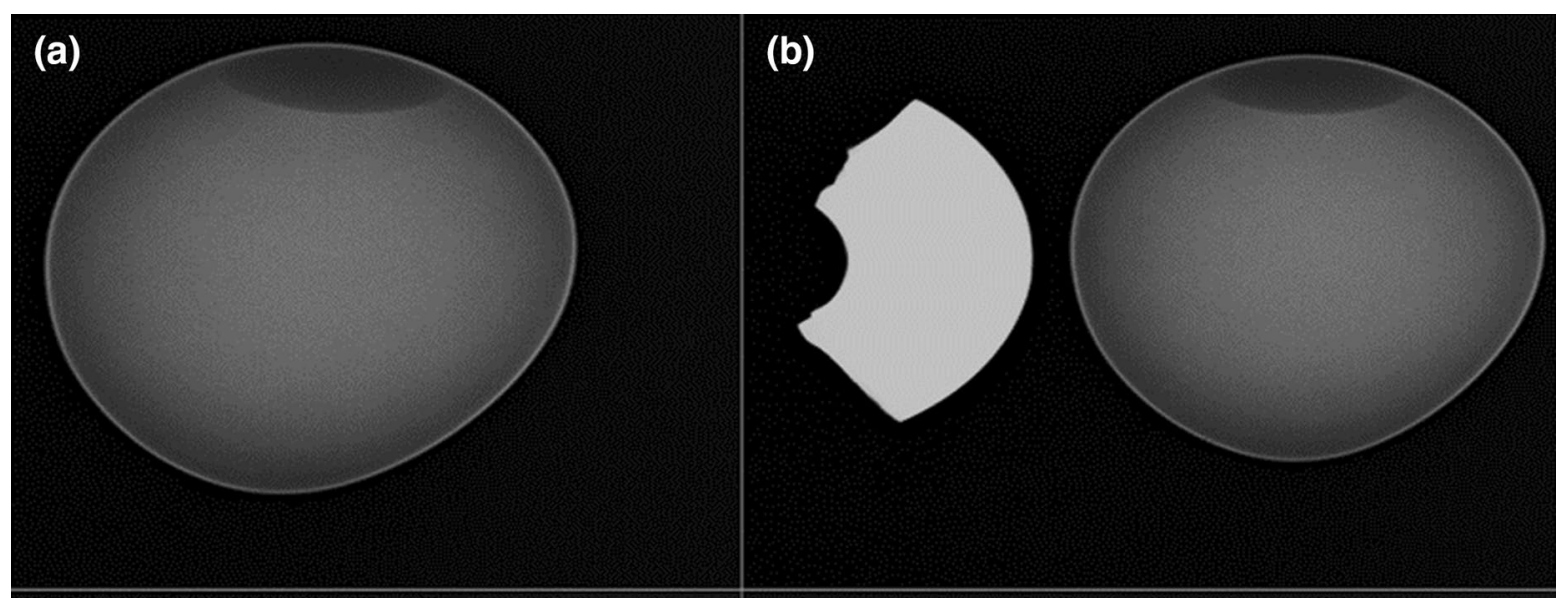

(c)

(d)
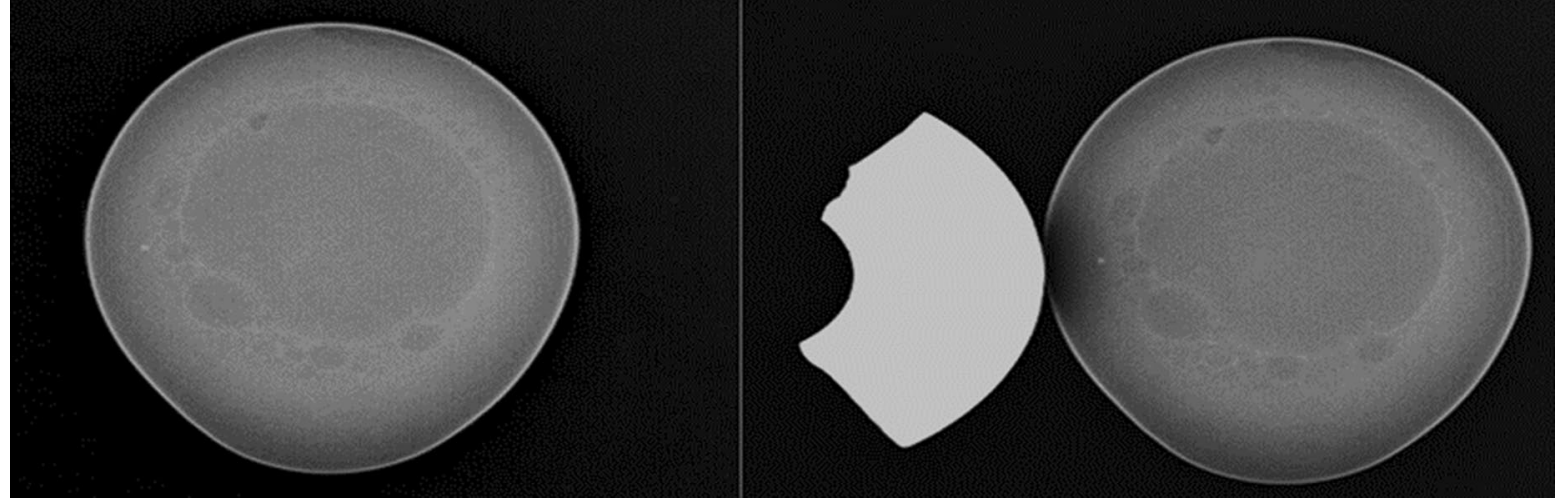

Fig. 11 X-ray imaging using chick eggs. a Control egg in the absence of magnetic field, $\mathbf{b}$ control egg in the presence of magnetic field, $\mathbf{c}$ egg injected with SPIONs in the absence of magnetic field, and $\mathbf{d}$ egg injected with SPIONs in the presence of magnetic field 
oxides are used in living system; it is less toxic and believed to be metabolized into haemoglobin [37-39].

\section{Conclusion}

Super-paramagnetic iron-oxide nanoparticles have been synthesized using Azadirachta indica leaf extract as one of the reducing agents. The synthesized particles were confirmed to be in the size range of $25 \mathrm{~nm}$ crystalline magnetite $\left(\mathrm{Fe}_{3} \mathrm{O}_{4}\right)$. SPIONs were effectively attracting the heavy metals and can be used in the treatment of wastewater for the removal of heavy metals and also as potent contrasting agents in X-ray imaging for diagnostic purposes.

Funding The work was not funded by any agency.

\section{Compliance with ethical standards}

Conflict of interest The authors confirm that there is no conflict of interest.

Open Access This article is distributed under the terms of the Creative Commons Attribution 4.0 International License (http://creativeco mmons.org/licenses/by/4.0/), which permits unrestricted use, distribution, and reproduction in any medium, provided you give appropriate credit to the original author(s) and the source, provide a link to the Creative Commons license, and indicate if changes were made.

\section{References}

1. Horikoshi, S.A., Serpone N.I.: Introduction to nanoparticles. In: Horikoshi, S., Serpone, N. (eds.) Microwaves in Nanoparticle Synthesis: Fundamentals and Applications, vol. 1, p. 1-24. Wiley, Weinheim (2013).

2. Khan, I., Saeed, K., Khan, I.: Nanoparticles: properties, applications and toxicities. Arab. J. Chem. (2017). https://doi. org/10.1016/j.arabjc.2017.05.011. (in press)

3. Murty, B.S., Shankar, P., Raj, B., Rath, B.B., Murday, J.: Textbook of Nanoscience and Nanotechnology. Springer Science \& Business Media, Berlin (2013)

4. Stark, W.J., Stoessel, P.R., Wohlleben, W., Hafner, A.: Industrial applications of nanoparticles. Chem. Soc. Rev. 44(16), 5793-5805 (2015)

5. Rajan, M., Krishnan, P., Pradeepkumar, P., Jeyanthinath, M., Jeyaraj, M., Ling, M.P., Arulselvan, P., Higuchi, A., Munusamy, A.M., Arumugam, R., Benelli, G., Murugan, K., Kumar, S.S.: Magneto-chemotherapy for cervical cancer treatment with camptothecin loaded $\mathrm{Fe}_{3} \mathrm{O}_{4}$ functionalized $\beta$-cyclodextrin nanovehicle. RSC Adv. 73, 46271-46285 (2017)

6. Elias, A., Tsourkas A.: Imaging circulating cells and lymphoid tissues with iron oxide nanoparticles. In: ASH Education Program Book, pp. 720-726. American Society of Hematology, Washington, DC (2009). https://doi.org/10.1182/asheducation-2009.1.720

7. Tratnyek, P.G., Johnson, R.L.: Nanotechnologies for environmental cleanup. Nano Today. 1(2), 44-48 (2006)
8. Li, L.H., Xiao, J., Liu, P., Yang, G.W.: Super adsorption capability from amorphousization of metal oxide nanoparticles for dye removal. Sci. Rep. 5, 9028 (2015)

9. Moussavi, G., Mahmoudi, M.: Removal of azo and anthraquinone reactive dyes from industrial wastewaters using $\mathrm{MgO}$ nanoparticles. J. Hazard. Mater. 168(2-3), 806-812 (2009)

10. Afkhami, A., Moosavi, R.: Adsorptive removal of Congo red, a carcinogenic textile dye, from aqueous solutions by maghemite nanoparticles. J. Hazard. Mater. 174(1-3), 398-403 (2010)

11. Xu, P., Zeng, G.M., Huang, D.L., Feng, C.L., Hu, S., Zhao, M.H., Liu, Z.F.: Use of iron oxide nanomaterials in wastewater treatment: a review. Sci. Total Environ. 424, 1-10 (2012)

12. Hua, M., Zhang, S., Pan, B., Zhang, W., Lv, L., Zhang, Q.: Heavy metal removal from water/wastewater by nanosized metal oxides: a review. J. Hazard. Mater. 211, 317-331 (2012)

13. Wahajuddin, S.A.: Superparamagnetic iron oxide nanoparticles: magnetic nanoplatforms as drug carriers. Int. J. Nanomed. 7, 3445 (2012)

14. Massart, R.: Preparation of aqueous magnetic liquids in alkaline and acidic media. IEEE Trans. Magn. 17(2), 1247-1248 (1981)

15. Wu, W., He, Q., Jiang, C.: Magnetic iron oxide nanoparticles: synthesis and surface functionalization strategies. Nanoscale Res. Lett. 3(11), 397 (2008)

16. Ali, A., Zafar, H., Zia, M., Haq, I.U., Phull, A.R., Ali, J.S., Hussai, A.: Synthesis, characterization, applications, and challenges of iron oxide nanoparticles. Nanotechnol Sci Appl. 9, 49-67 (2016)

17. Justin, C., Samrot, A.V., Sruthi, P.D., Sahithya, C.S., Bhavya, K.S., Saipriya, C.: Preparation, characterization and utilization of coreshell super paramagnetic iron oxide nanoparticles for curcumin delivery. PLoS ONE 13(7), e0200440 (2018)

18. Sheng-Nan, S., Chao, W., Zan-Zan, Z., Yang-Long, H., Venkatraman, S.S., Zhi-Chuan, X.: Magnetic iron oxide nanoparticles: synthesis and surface coating techniques for biomedical applications. Chin. Phys. B. 23(3), 037503 (2014)

19. Samrot, A.V., Justin, C., Padmanaban, S., Burman, U.: A study on the effect of chemically synthesized magnetite nanoparticles on earthworm: Eudrilus eugeniae. Appl. Nanosci. 7(1), 17-23 (2017)

20. Kalaiarasi, R., Jayallakshmi, N., Venkatachalam, P.: Phytosynthesis of nanoparticles and its applications. Plant Cell Biotechnol. Mol. Biol. 11(1/4), 1-16 (2010)

21. Jha, A.K., Prasad, K., Prasad, K., Kulkarni, A.R.: Plant system: nature's nanofactory. Colloids Surf. B 73(2), 219-223 (2009)

22. Weber Jr., W.J., McGinley, P.M., Katz, L.E.: Sorption phenomena in subsurface systems: concepts, models and effects on contaminant fate and transport. Water Res. 25(5), 499-528 (1991)

23. Jahan, M.A.A., Akhtar, N., Khan, N.M.S., Roy, C.K., Islam, R., Nurunnabi, : Characterization of tannery wastewater and its treatment by aquatic macrophytes and algae. Bangladesh J. Sci. Ind. Res. 49(4), 233-242 (2014)

24. Johnson, J., Schewel, L., Graedel, T.E.: The contemporary anthropogenic chromium cycle. Environ. Sci. Technol. 40, 7060-7069 (2006)

25. Awwad, A.M., Salem, N.M.: A green and facile approach for synthesis of magnetite nanoparticles. Nanosci. Nanotechnol. 2(6), 208-213 (2012)

26. Wang, X., Niessner, R., Knopp, D.: Magnetic bead-based colorimetric immunoassay for aflatoxin B1 using gold nanoparticles. Sensors 14(11), 21535-21548 (2014)

27. Khalil, M.: Co-precipitation in aqueous solution synthesis of magnetite nanoparticles using iron (III) salts as precursors. Arab. J. Chem. 85(2), 279-284 (2015)

28. Justin, C., Philip, S.A., Samrot, A.V.: Synthesis and characterization of superparamagnetic iron-oxide nanoparticles (SPIONs) and utilization of SPIONs in X-ray imaging. Appl. Nanosci. 7(7), 463-475 (2017) 
29. Liang, M.T., Wang, S.H., Chang, Y.L., Hsiang, H.I., Huang, H.J., Tsai, M.H., Juan, W.C., Lu, S.F.: Iron oxide synthesis using a continuous hydrothermal and solvothermal system. Ceram. Int. 36, 1131-1135 (2010)

30. Chourpa, I., Douziech-Eyrolles, L., Ngaboni-Okassa, L., Fouquenet, J.F., Cohen-Jonathan, S., Soucé, M., Dubois, P.: Molecular composition of iron oxide nanoparticles, precursors for magnetic drug targeting, as characterized by confocal Raman microspectroscopy. Analyst 130(10), 1395-1403 (2005)

31. Schütt, W., Grüttner, C., Häfeli, U., Zborowski, M., Teller, J., Putzar, H., Schümichen, C.: Applications of magnetic targeting in diagnosis and therapy-possibilities and limitations: a minireview. Hybridoma 16(1), 109-117 (1997)

32. Márquez, F., Herrera, G.M., Campo, T., Cotto, M., Ducongé, J., Sanz, J.M., Elizalde, E., Perales, O., Morant, C.: Preparation of hollow magnetite microspheres and their applications as drugs carriers. Nanoscale Res. Lett. 7, 210 (2012)

33. Bhattacharjee, S.: DLS and zeta potential-what they are and what they are not? J. Controlled Release. 235, 337-351 (2016)

34. Horie, M., Iwahshi, H.: The impact of the physiochemical properties of manufactured nanoparticles on in vitro and in vivo evaluation of particle toxicity. J. Phys. Chem. Biophys. 4(2), 139 (2014)
35. Martinez-Boubeta, C., Simeonidis, K., Makridis, A., Angelakeris, M., Iglesias, O., Guardia, P., Saghi, Z.: Learning from nature to improve the heat generation of iron-oxide nanoparticles for magnetic hyperthermia applications. Sci. Rep. 3, 1652 (2013)

36. Lanas, S.I.G.: Fluoride and metal ions removal from water by absorption on nanostructured materials. Ph.D. thesis in chemistry in environmental and energy engineering science. Universitat Autonoma de Barcelona (2017)

37. Laurent, S., Forge, D., Port, M., Roch, A., Robic, C., Vander Elst, L., Muller, R.N.: Magnetic iron oxide nanoparticles: synthesis, stabilization, vectorization, physicochemical characterizations, and biological applications. Chem. Rev. 108(6), 2064-2110 (2008)

38. Gupta, A.K., Gupta, M.: Synthesis and surface engineering of iron oxide nanoparticles for biomedical applications. Biomaterials 26(18), 3995-4021 (2005)

39. Rosen, J.E., Chan, L., Shieh, D.B., Gu, F.X.: Iron oxide nanoparticles for targeted cancer imaging and diagnostics. Nanomed. Nanotechnol. Biol. Med. 8(3), 275-290 (2012)

Publisher's Note Springer Nature remains neutral with regard to jurisdictional claims in published maps and institutional affiliations. 